\title{
Professor Emérito João Claudio Todorov
}

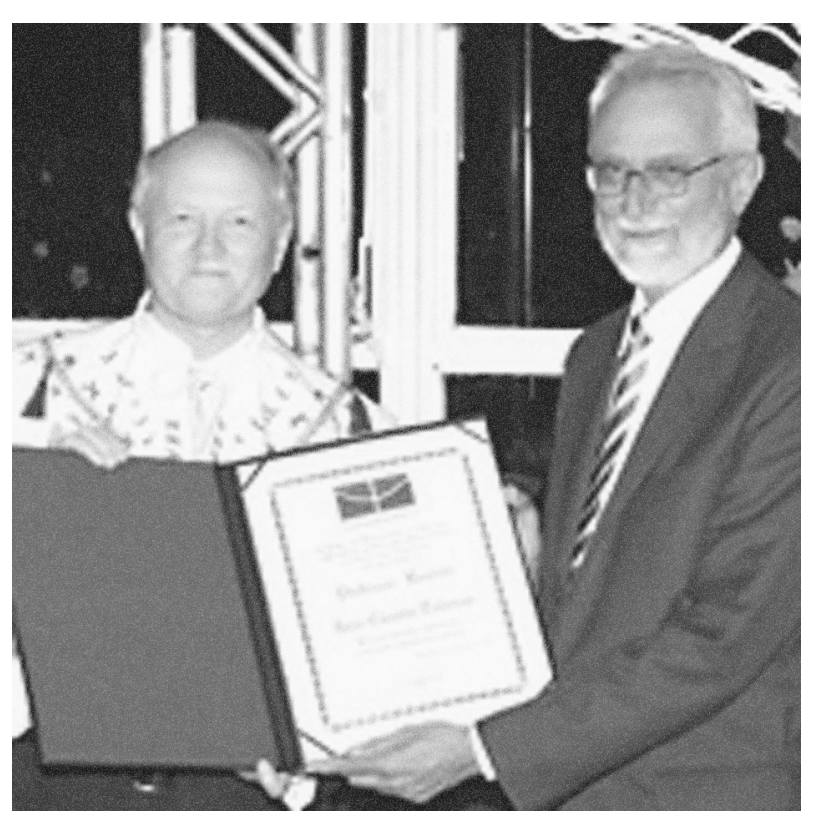

Figura 1. Professor Emérito João Claudio Todorov recebendo a premiação das mãos do reitor da Universidade de Brasília, Professor Timothy Mulholland.

Fonte:_http://www.unb.br/acs/unbagencia/imagens/ag0306-66f5.jpg

\section{Proposta de Concessão do Título de Professor Emérito ao Professor Dr. João Claudio Todorov ${ }^{1}$}

Tendo como base as substanciais contribuições do professor João Claudio Todorov, no desenvolvimento e solidificação da Psicologia como disciplina científica no Brasil e principalmente as suas contribuições acadêmicas e administrativas junto á Universidade de Brasília, o Departamento de Processos Psicológicos Básicos vem propor a concessão do título de Professor Emérito ao professor Todorov.

O professor Todorov iniciou sua carreira acadêmica em Psicologia no ano de 1960 quando ingressou no curso de Psicologia na Universidade de São Paulo, tendo obtido o título de bacharel em 1962 e o de licenciatura em 1963. Após uma passagem por Brasília, junto com a equipe formada pelos professores Fred S. Keller e Carolina Martusceli Bori, responsáveis pela fundação do Departamento de Psicologia da UnB, o professor Todorov iniciou seus estudos de doutorado na Arizona State University, USA, em 1965, sob a orientação do Dr. Stanley S. Pliskoff, onde obteve o título de Ph.D. em 1969.

Antes de retornar em definitivo para a UnB, em 1973, o professor Todorov exerceu atividade de ensino e pesquisa no Institut For Behavior Research, em Maryland, USA, na University of Virginia, USA, e na Universidade de São

1 Texto produzido pelos professores do Departamento de Processos Psicológicos Basicos da Universidade de Brasília para subsidiar processo de proposta de outorga do título de Professor Emérito da Universidade de Brasília. A editora agradece ao Departamento pela cessão deste texto para publicação.
Paulo, campus de Ribeirão Preto. Em 1977 foi professor visitante da Universidad Nacional Autónoma de México, UNAM, e durante o ano de 1990 foi fellow da Fullbrith da State University of New York, USA. Na UnB, criou o laboratório de Análise Experimental do Comportamento, onde desenvolveu uma longa e profícua trajetória de pesquisa, tornando o laboratório referencia nacional na área. Em 2000 aposentou-se da Universidade de Brasília, mas continuou a contribuir com o Departamento de Processos Psicológicos Básicos, como pesquisador associado, orientando alunos de mestrado e doutorado e de iniciação científica, contribuição esta ainda em andamento. Hoje, suas atividades acadêmicas incluem vínculos com a Universidade Católica de Goiás e com o Instituto de Ensino Superior de Brasília.

Durante sua carreira, o professor Todorov publicou 77 artigos científicos em revistas nacionais e internacionais, além de 11 capítulos e a organização de um livro. Um de seus artigos, publicado em 1973 no Journal of the Experimental Analysis of Behavior se tornou citação obrigatória nos estudos sobre esquemas concorrentes e lei de igualação. $\mathrm{Na}$ área de publicações, sua contribuição aparece como um dos fundadores da revista Psicologia: Teoria e Pesquisa em 1985, da qual se tornou editor alguns anos mais tarde, além da participação em conselhos editoriais em várias revistas nacionais e internacionais, como a própria Journal of the Experimental Analysis of Behavior e da Behavior and Philosophy, revistas expoentes na Análise de Comportamento. Mais recentemente, 
em 2004, ajudou a fundar a Revista Brasileira de Análise do Comportamento - Brazilian Journal of Behavior Analysis, da qual é seu primeiro editor.

$\mathrm{Na}$ área de formação de recursos humanos, o professor Todorov orientou 18 dissertações de mestrado e cinco teses de doutorado, além de 19 alunos de iniciação científica, isso sem contar as dezenas de orientações de alunos de graduação não registradas formalmente como tal. Vários de seus exalunos ocupam hoje, além de posições acadêmicas, papéis de destaque na condução da Psicologia científica no Brasil.

Além das contribuições acadêmicas de ensino e pesquisa, sua atuação política teve também contribuições importantes na área profissional tanto do psicólogo como do docente. Teve importante participação na criação do Conselho Regional de Psicologia, $1^{\text {a }}$ Região, que inclui o Distrito Federal, sendo seu registro histórico de membro 001 daquele conselho. Teve também importante contribuição na fundação da Associação dos Docentes da Universidade de Brasília, em 1978, da qual foi o primeiro presidente.

A participação do professor Todorov foi também importante no desenvolvimento de sociedades científicas no Brasil, principalmente na área da Psicologia. Em 1971, foi um dos fundadores da Sociedade de Psicologia de Ribeirão Preto, hoje Sociedade Brasileira de Psicologia, tendo sido seu primeiro vice-presidente. Entre outras, foi conselheiro da Sociedade Brasileira para o Progresso da Ciência, e mais recentemente teve atuação destacada para a criação do capítulo Brasil da Association for Behavior Analysis, a principal associação internacional de Análise do Comportamento. Além de suas contribuições acadêmicas de ensino e de pesquisa, o professor Todorov teve uma contribuição administrativa significativa na Universidade de Brasília. Entre suas contribuições administrativas, devemos destacar sua atuação como reitor da UnB no período de 1993 a 1997. Outras atuações significativas incluem: decano de pesquisa e pós-graduação, em 1985; vice-reitor de 1985 a 1989; chefe do Departamento de Processos Psicológicos Básicos, de 1991 a 1993; e diretor do Centro de Excelência em Turismo, de 1999 a 2001.

A trajetória do professor João Claudio Todorov demonstra sua constante contribuição para o desenvolvimento da Psicologia como disciplina científica no Brasil, em especial a Análise do Comportamento. Além da produção de conhecimento, ensino e formação de recursos humanos, sua participação administrativa foi também fundamental para a luta e a manutenção de um ensino superior público de qualidade, ajudando a consolidar o papel histórico da UnB na defesa desses ideais. Assim, o Departamento de Processos Psicológicos Básicos sente-se privilegiado em ter podido contar com a sua valiosa participação em seus quadros, e com muito orgulho e satisfação encaminha esta proposta de concessão, pela UnB, do título de Professor Emérito ao estimado colega, Professor Doutor João Claudio Todorov. 